\title{
Unravelling Methodologies for a Rational Lignin Valorisation Using Heterogeneously Catalysed Protocols
}

\author{
Rafael Luque*
}

\author{
Departamento de Química Orgánica, Universidad de Córdoba, Campus de Excelencia Agroalimentario \\ (CeiA3) de Rabanales, Ctra Nnal IV-A, Km 396, E-14014 Córdoba, Spain
}

\begin{abstract}
Lignin depolymerisation has recently a great deal of attention from scientists and companies worldwide due to the extensive possibilities of this recalcitrant material for the production of chemicals, fuels and materials. The natural complexity and stability of lignin bonds makes lignin depolymerization a highly challenging task. Several efforts have been directed towards a more profound understanding of the structure and composition of lignin in order to devise pathways and selectively cleave bridging bonds to break down the biopolymer into useful compounds. The present contribution aims to provide a series of key points in the field of lignin depolymerisation to provide an overview to the field for starting researchers.
\end{abstract}

Keywords: Lignin, depolymerisation, heterogeneous catalysis, chemicals, fuels, materials.

Lignin is one of the major and most abundant biopolymers in nature which has a protecting and structural role in plants. The reason behind its structural function is related to its recalcitrance, originated by the stability of the polymeric structure through the various present linkages (Scheme 1). Nevertheless, lignin valorisation practises have attracted a great deal of interest in recent years due to the recognised potential of this renewable and highly abundant biomass resource as natural source of aromatics.

Several efforts in the area of lignin depolymerisation can be found in recent literature reports. These have been generally based on two main approaches: oxidation and hydrotreating (hydrogenolysis) related protocols [1, 2]. In some case, degradation with enzyme cocktails have also been described [3]. However, to date, reported lignin depolymerisation approaches are mostly limited to the use of lignin model compounds of low complexity, including some recently promising results of the use of $\mathrm{Ni}$ homogeneous systems by Hartwig et al. [4], while only a few very recent protocols that can achieve a selective production of simple aromatic compounds in high yields from crude lignin can be found to date $[1,5,6]$. These protocols entail high temperatures $250-600^{\circ} \mathrm{C}$ and pressures in some cases and generally led to a complex phenolic mixture of polyhydroxylated and alkylated phenol compounds together with significant quantities of char and volatiles [6].

*Address correspondence to this author at the Departamento de Química Orgánica, Universidad de Córdoba, Campus de Excelencia Agroalimentario (CeiA3) de Rabanales, Ctra Nnal IV-A, Km 396, E-14014 Córdoba, Spain; Tel: +34 957211050; Fax: +34 957212066; E-mail: q62alsor@uco.es
Depolymerisation processes are often not well understood. This is already a highly challenging task for enzymatic-based methodologies, let alone for heterogeneously catalysed protocols. A series of considerations for the rational design of heterogeneous catalysts for lignin depolymerisation practises are disclosed in this contribution, aiming to provide a starting point for scientists commencing biomass and/or lignin research as well as a guideline model to the scientific community to stimulate advances and progress on lignin valorisation using heterogeneous catalysts.

Taking a look at general methodologies and reported approaches, there are two main considerations that should be taken into account for lignin valorisation purposes which most of the literature reports have generally overlooked to date. These include 1) a maximisation of the activity of the catalyst under the chosen conditions (as mild as possible), bearing in mind the bulky nature of this biomass recalcitrant source and 2) most importantly the repolymerisation and self-condensation capability of lignin under processing conditions (due to the formation of radicals [7] and/or C-C bond forming self-condensation reactions in acidic media [8]) which may eventually lead to a complex pool of poorly controllable re-condensed aromatics as demonstrated by several groups worlwide [1, 7-9]. In other cases, depolymerisation is more or less achieved giving a pool of relatively simple aromatics under generally harsh reaction conditions and low yields to products $(<50 \%)$ $[1,2,5,6,8]$.

Radical formation and undesirable lignin selfcondensation processes have to be minimised to avoid 


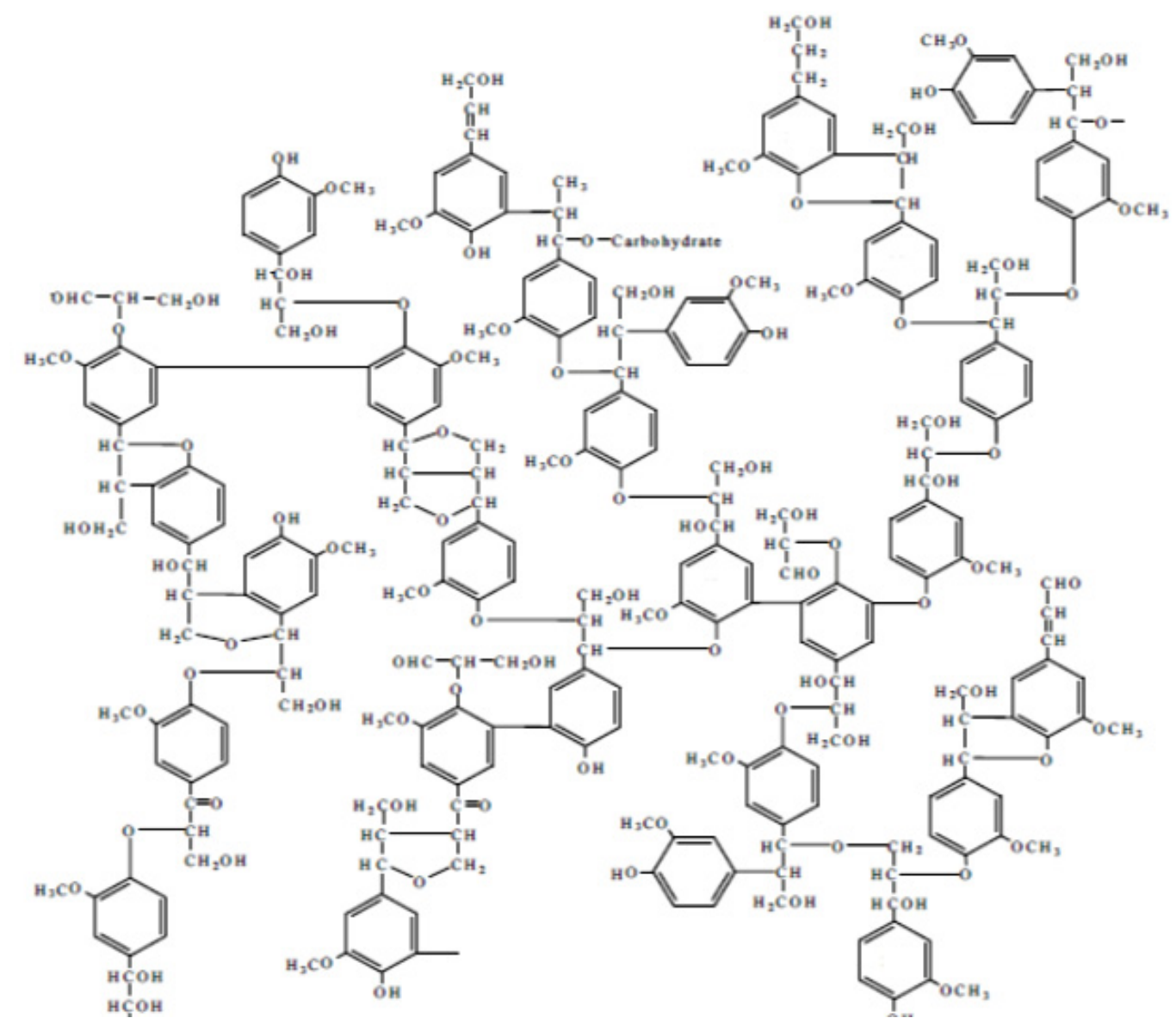

Scheme 1: Overview of the chemical structure of softwood native lignin proposed by Sakakibara (1980) showing the typical C-C and $\mathrm{C}-\mathrm{O}$ bond linkages between aromatic and aliphatic parts.

lignin repolymerisation, maximising at the same time the accesibility and activity of active sites to the bulky lignin molecules. Both of these may be achievable by designing tailored nanomaterials based on fundamental understanding. In terms of lignin chemistry, there are two main and essentially different linkages to target and several reactions that should be taken into account. Firstly, and most importantly, the catalyst should have metal sites for the hydrogenolysis of $\alpha$ and $\beta$-aryl-alkyl and aryl-aryl ether linkages (Scheme 2).

Recent research reports indicate that beta-type linkages ( $\beta-\mathrm{O}-4$, aryl-alkyl ether bonds) seem to be the weakest bonds in $\mathrm{C}-\mathrm{O}$ ether linkages in lignin, as compared to the highly stable aryl-aryl ether bonds [1013]. Comparatively, both aryl-aryl and aryl-alkyl C-C linkages are generally more stable and can only be efficiently cleaved under very particular and often harsh conditions (e.g. $400^{\circ} \mathrm{C}$, base catalysis) [11-13]. The use of oxidants and/or oxidising approaches can be highly desirable only if the presence of radicals species can be controlled as these will lead to partial re-polimerisation of lignin and thus to more complex structures. Reactions under hydrotreating conditions (e.g. using hydrogen donating solvents, hydrogenolysis in the presence of hydrogen) can comparatively favour quenching and recombination of radicals, minimising lignin repolymerisation side processes while maximising $\mathrm{C}-\mathrm{O}$ bond cleavage. Recently, boric acid has also been found to be a promising capping agent to minimise the addition and condensation of initially formed products under base-catalysed lignin processing [11]. The proposed combination swicthed the products distribution to low molecular weight compounds (typically syringol and derivatives) and increased product yields above $85 \%$.

$\mathrm{Rh}, \mathrm{Pt}$ and $\mathrm{Pd}$ are among the most widely utilised metals for the transformations of lignin model compounds $[5,8,14]$, while the promising potential of $\mathrm{Ni}$ in $\mathrm{C}-\mathrm{O}$ bond cleavage was overlooked until very recently $[4,5,15]$. In fact, Li et al. reported the use of a carbon supported $\mathrm{Ni}-\mathrm{W}_{2} \mathrm{C}$ catalyst for the direct 


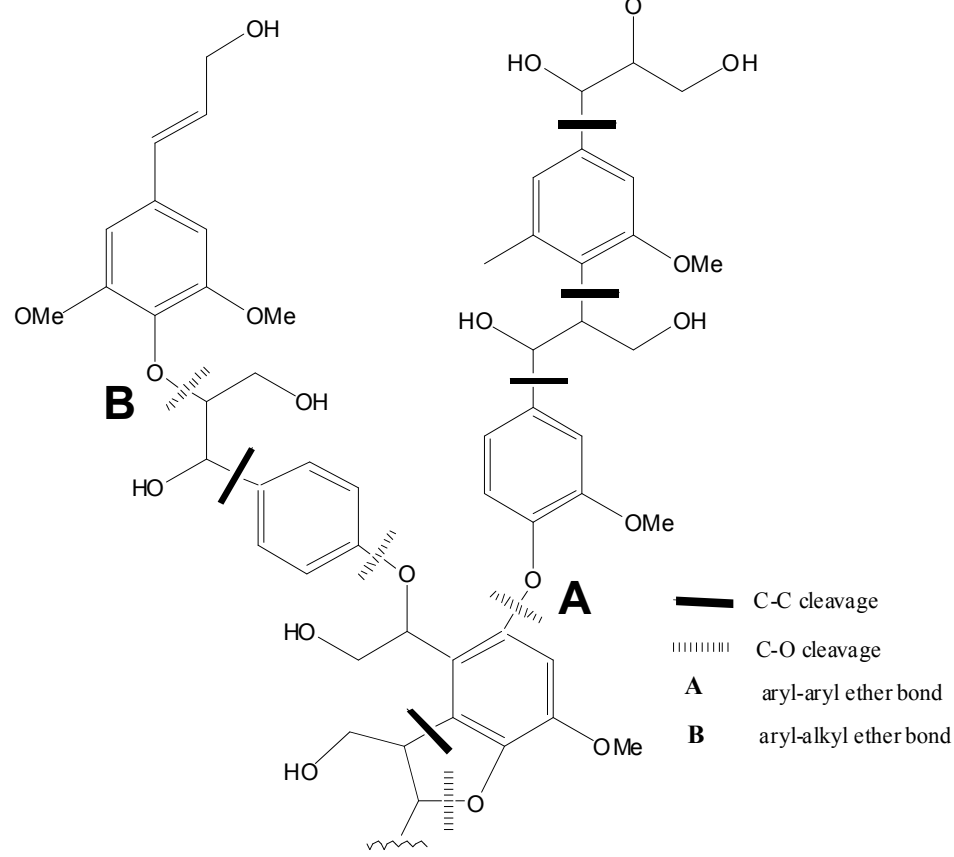

Scheme 2: Targetting C-C and C-O bond cleavage in lignin: the depolymerisation strategy. Adapted from reference [8].

catalytic conversion of raw woody biomass (e.g. birch, poplar, pine and related feedstocks) into monophenols up to $46.5 \%$ yield (based on lignin) without any pretreatment step [5]. The authors showed this type of catalyst exhibited a comparable activity to that of noble metals, paving the way to a further development of $\mathrm{Ni}$ based materials for lignin depolymerisation.

Another important aspect to consider is the optimisation of hydrogen addition in the systems, which could lead to an undesirable partial or complete hydrogenation of the aromatic rings in the presence of the metal sites [16]. This will contribute not only to the poor hydrogen economy of the methodology but also to less interesting and valuable compounds.

Thirdly, but not less importantly, the presence of acid sites in the catalyst can offer the additional possibility of dealkylation and/or deacylation-related reactions (Scheme 3) [8, 11-13], which in combination with aryl ether bond cleavage, could ultimately lead to very simple aromatic compounds including syringaldehyde, mesitol, guaiacol and related chemicals. Acid sites might also cleave lignin ether bonds but less efficiently compared to metal sites [8]. The nature and strength of the acidity needs also to be

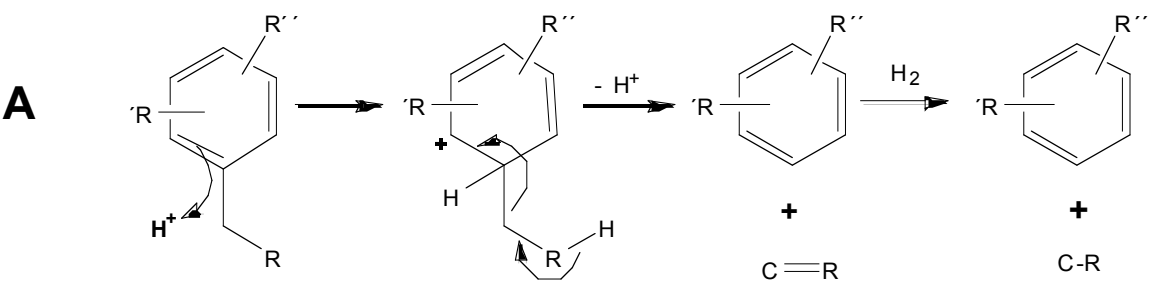

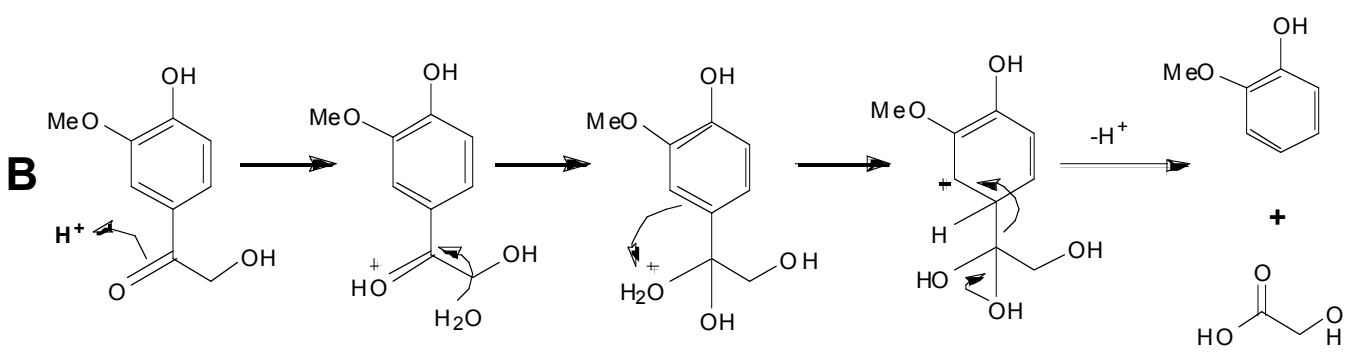

Scheme 3: Proponed acid-catalysed mechanisms for A) hydrogenolysis of aromatic derivatives via dealkylation and B) deacylation of lignin-derived compounds. Adapted from reference [8]. 
carefully controlled as to avoid secondary lignin selfcondensation undesirable reactions [8, 11-13].

These have also been minimised by using reactive solvents (e.g. water, phenol, cresols) and/or other capping agents (e.g. boronic acid) with the possibility to cap reactive sites on lignin to prevent its cross-linking $[8,11,17]$. Zeolites have been extensively employed as acidic supports combined with a metallic phase (e.g. $\mathrm{Pt}, \mathrm{Pd}$ ) generally leading to good to excellent results with lignin model compounds. This has been attributed to their combination of Brönsted (preferentially) and Lewis acid sites [18]. Active site accessibility and activity in the utilisation of bulky lignin molecules for such microporous materials raises serious concerns for their successful utilisation in lignin depolymerisation, but in principle a good balance between Brönsted and Lewis acidity and moderate to strong acid sites seem to the key to promote dealkylation and related processes.

\section{FUTURE PROSPECTS AND OUTLOOK}

In the light of these premises, a carefully and rationally designed bifunctional catalyst combining metal (efficient for C-O bond cleavage) and acid sites (for dealkylation and related deacylation reactions) seem to plausibly provide the required prerequisites for lignin depolymerisation. They key steps of the process entail the maximisation of the accesibility and activity of the metal and acid sites in the catalyst as well as to avoid/minimise the re-polymerisation of the final products generated in solution during the depolymerisation steps. Due to the large variety of active centers for cleavage, researchers are advised to focus on cleaving specific groups (e.g. the less recalcitrant and most abundant $\beta-\mathrm{O}-4$ aryl-alkyl ether bonds) and develop the science for specific approaches as these also are highly dependent on the type of lignin (variable starting structures have lignin specific chemistries) [19].

Additionally, the future in lignin valorisation may be also related to the interesting possibilities of heterogeneous photocatalysts and the possibility to utilise sunlight to deconstruct lignin into valuable aromatics [20].

The author hopes the present contribution can serve as starting point as well as encouragement to scientists worldwide to redouble their efforts and endeavours on lignin depolymerisation practises to valuable compounds. The proposed methodologies are believed to possess a great potential for further development and most importantly can pave the way to advanced valorisation practises of lignin as renewable and sustainable source of simple aromatics.

\section{ACKNOWLEDGEMENTS}

RL gratefully acknowledges Ministerio de Ciencia e Innovacion, Gobierno de España for the concession of a Ramon y Cajal contract (ref. RYC-2009-04199) and funding under project CTQ2011-28954-C02-02 as well as Consejeria de Ciencia e Innovacion, Junta de Andalucia for funding under the project P10-FQM6711.

\section{REFERENCES}

[1] Zakzeski J, Bruijnincx PCA, Jongerius AL, Weckhuysen BM Chem Rev 2010; 110: 3552-3599. http://dx.doi.org/10.1021/cr900354u

[2] Pandey MP, Kim CS. Chem Eng Technol 2011; 34: 29-41. http://dx.doi.org/10.1002/ceat.201000270

[3] a) Aizenshtadt MA, Bogolitsyn KG. Khimiya Rastitel'nogo Syr'ya 2009; 5-18;

b) Zoia L, Orlandi M, Argyropoulos DS. J Agricultural Food Chem 2008; 56: 10115-10122;

http://dx.doi.org/10.1021/jf801955b

c) Guerra A, Norambuena M, Freer J, Argyropoulos DS. J Natural Prod 2008; 71: 836-841;

http://dx.doi.org/10.1021/np800080s

d) Crestini C, Argyropoulos DS. Bioorg Med Chem 1998; 6: 2161-2169.

http://dx.doi.org/10.1016/S0968-0896(98)00173-4

[4] Sergeev AG, Hartwig JF. Science 2011; 332: 439-442. http://dx.doi.org/10.1126/science.1200437

[5] Li C, Zheng M, Wang A, Zhang T. Energy Environ Sci 2012 5: 6383-6390.

http://dx.doi.org/10.1039/C1EE02684D

[6] Gosselink RJA, Teunissen W, van Dam JEG, De Jong E, Gellerstedt G, Scott EL, Sanders JPM. Biores Technol 2012; 106: 173-177.

http://dx.doi.org/10.1016/j.biortech.2011.11.121

[7] a) Argyropoulos DS. Proceedings of the Internationa Chemical Congress of Pacific Basin Societies (Pacifichem), Honolulu (Hawai), USA, December 2010;

b) Nakamura T, Kawamoto H, Saka S. J Wood Chem Technol 2007; 27: 121-133

http://dx.doi.org/10.1080/02773810701515143

[8] Binder JB, Gray MJ, White JF, Zhang ZC, Holladay JE. Biomass Bioenergy 2009; 33: 1122-1130.

http://dx.doi.org/10.1016/j.biombioe.2009.03.006

[9] Guerra A, Filpponen I, Lucia LA, Saquing C, Baumberger S, Argyropoulos DS. J Agricultural Food Chem 2006; 54: 59395947.

http://dx.doi.org/10.1021/jf060722v

[10] a) Gnanakaran S. Abstracts of the $242^{\text {nd }}$ American Chemica Society National Meeting, Denver, Colorado, 2011;

b) Kandanarachchi PH, Autrey T, Franz JA. J Org Chem 2002; 67: 7937-7945.

http://dx.doi.org/10.1021/jo025581k

[11] Roberts VM, Knapp RT, Li X, Lercher JA. ChemCatChem 2010; 2; 1407-1410.

[12] Roberts VM, Knapp RT, Li X, Lercher JA. Appl Catal B 2010 95: 71-77.

http://dx.doi.org/10.1016/j.apcatb.2009.12.010 
[13] Roberts VM, Stein V, Reiner T, Lemonidou A, Li X, Lercher JA. Chem Eur J 2011; 17: 5939-5948. http://dx.doi.org/10.1002/chem.201002438

[14] a) Liguori L, Barth T. J Anal Appl Pyrolysis 2011; 92: 477484;

http://dx.doi.org/10.1016/j.jaap.2011.09.004

b) Yan N, Zhao C, Dyson PJ, Wang C, Liu L, Kou Y. ChemSusChem 2008; 1: 626-629.

http://dx.doi.org/10.1002/cssc.200800080

[15] Horacek J, Homola F, Kubickova I, Kubicka D. Catal Today 2012; 179: 191-198.

http://dx.doi.org/10.1016/j.cattod.2011.06.031

[16] Wang $X$, Richter $U$, Rinaldi R. Proceedings of the $1^{\text {st }}$ International Conference on Catalysis for Biorefineries, Malaga (Spain) 2011.
[17] a) Hepditch MM, Thring RW. Canadian J Chem Eng 2000; 78: 226-231;

http://dx.doi.org/10.1002/cjce.5450780129

b) Vouri A, Niemela M. Holzforschung 1988; 42: 327-334; http://dx.doi.org/10.1515/hfsg.1988.42.5.327

c) Davoudzadeh F, Smith B, Avni E, Coughlin RW Holzforschung 1985; 39: 159-166.

http://dx.doi.org/10.1515/hfsg.1985.39.3.159

[18] Corma A. Chem Rev 1995; 95: 559-614 http://dx.doi.org/10.1021/cr00035a006

[19] Koda K, Gaspar AR, Yu L, Argyropoulos DS. Holzforschung 2005; 59: 612-619.

http://dx.doi.org/10.1515/HF.2005.099

[20] Green Photo-active Nanomaterials: Sustainable Energy and Environmental Remediation, Eds. N. Nuraje, R. Asmatulu, G. Mul, RSC Green Chemistry Series 2016. 